\title{
IMAGINATION OF BORDERLESS WORLD: IMPACT ON QUALITY OF LIFE
}

\author{
Prakash Kumar Kaushik \\ Bilaspur C.G. India
}

\begin{abstract}
The main aim of this paper is to analyze how a world without border will be like. About individuals independence and quality of life and access to all important medications and there will be no war reduced death by hunger and diseases and human rights are properly applied.
\end{abstract}

\section{INTRODUCTION}

Border is a line separating two countries and administrations. Only because of this single line people are separated, Communities are separated. Human rights vary according to country and health care also vary according to country and due to border people get varying education like which is quality education in America, Canada and schengen area and because of quality education country growth goes higher and low income countries are not able to provide quality education and thus the country growth is not appropriately stable. Human rights are affected in low income countries such as (Philippines) in low income countries. Woman's are still deprived of equal parental authority, Property right and Muslim woman do no benefit from the family codes advancements because they are subjected to separated code of Muslim personal law additionally Muslim woman's are denied the ability to choose their profession, domestic role and residence and receive limited access to court. Thus due to border many people's are deprived from quality of life and human rights. Even though peoples in undeveloped areas can't get medication for disease which is very common and treatable in other developed

Countries. And also because of that medicine is not licensed. In the world every year about 9 million people get died from hunger. Which is more than

combined death of AIDS, Malaria,tb.3.1 million child get death due to hunger and hunger related disease at the age of 5 years. In some countries abortion is illegal even if someone is raped she can't abort it but by globalization it could be legal. Global defense budget is about 1.917 trillion but if all country become unity they will not fight with each other's and this budget can be utilized to give quality education and globalization also lead to even distribution of wealth. There are much examples such as America(U.S.), Canada, Schengen area etc but in us wealth is not even distributed but there no much migration from poor to rich areas. and in schengen area you can visit all 26 European countries in one visa and also transport goods completely unnoticed before schengen area it takes about hours to pass borders.

\section{OBJECTIVE}

1. To implement the quality of life.

2. To access all resources' properly.

\section{METHOD}

A relative study was carried out by prakash kumar kaushik during un lock 2.0(covid-19) In This relative analysis of imagination of borderless world: Impact on Quality of life and analysis of schengen area, U.S. and Canada as borderless world have done through online data collection after data collection it was entered in excel sheet in form of tables and charts and results were represented in the form of figures.

\section{RESULT}

It is observed from the study data that globalization or borderless world could help various people and mostly healthcare an society affected humans and implement quality of life thus quality education quality of life thus quality education and quality law etc.

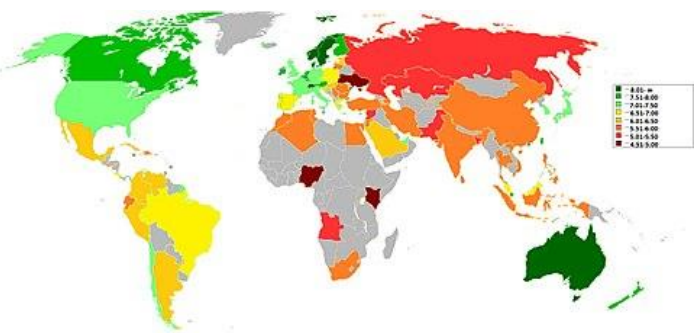




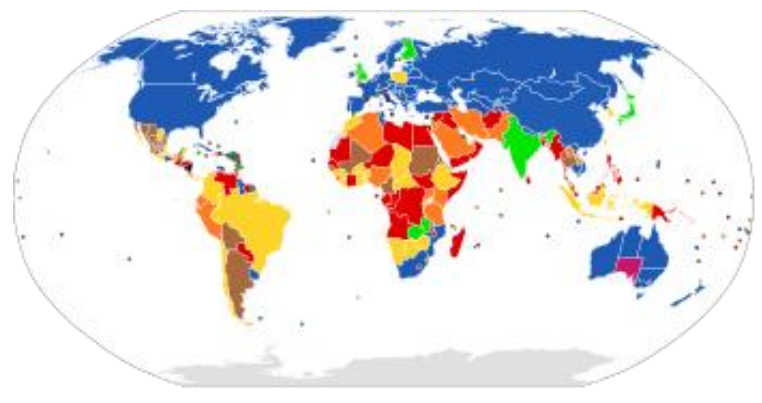

International status of abortion law. In some cases, this map may not accurately depict the content of this article. ${ }^{[1]}$

\section{Legal on request}

Restricted to cases of maternal life, mental health, physical health, rape, fetal defects, and/or socioeconomic factors

Restricted to cases of maternal life, mental health, physical health, rape and/or fetal defects

$\square$ Restricted to cases of maternal life, mental health, physical health and/or rape

$\square$ Restricted to cases of maternal life, mental health and/or physical health

$\square$ Restricted to cases of maternal life, mental health and/or physical health, and/or fetal defects

$\square$ Restricted to cases of maternal life

$\square$ Illegal with no exceptions

No information

\section{CONCLUSION}

- In present study the healthcare assistance and quality of life in schengen area, Canada and us are ideal for global and borderless world and it needs to be applied in all over the world so that all people in the world can get same rights and equality.

\section{AKNOWLEDGMENT}

I would like to express my deep and sincere gratitude to my parents and web services and also i am extremely grateful to my parents for their love, caring and sacrifices for educating and preparing me for my future.

\section{REFERENCE}

1. Gipson j. d. et al (2011).Perception and Practices of illegal Abortion among urban Young Adults in the
Philippines: A Quantitative Study. (DOI.10.1111/j.1728-4465.2011.00289.x)

2. C Padmapriyadarsini et al.(2016). Under nutrition and Tuberculosis in India: Situation Analysis and The Way Forward.(DOI.10.4103/0971-5916.193278).

3.Ferreira L.S. et al (2011).Under nutrition as a Major Risk Factor for Death Among Older Brazilian Adults in the Community-Dwelling Setting: SABE Survey.(DOI.10.1016/j.net.2010.11.008).

4. Royal k. d. et al.(2017).Quality Teaching Matters More Than Innovation curricula.(DOI.10.1016/j.amjmed.2016.11.014).

5. Knezevic I et al.(2011).Biosimilars--Global Issues National

Solution.(DOI.10.1016/j.Biologicals.2011.09.005).

6. Younger D. S. et al.(2016).Healthcare in India (DOI.10.1016/j.ncl.2016.06.005).

7.Capanzana M.V. et al.(2018).Nutritional Status of Children Ages 0-5 and 5-10 years old in household headed by fisherfolks in the Philippines.(DOI.10.1186/s13690-018-0267-3).

8. Der H. A. et al (2017). Revisiting the AIDS epidemic in Pakistan Where We Stand and What we Must AIm for (DOI.10.1089/AID.2017.0042).

9.Shapiro G.K.(2014).Abortion Law In MuslimMajority Countries: An Overview of the Islamic Discourse with policy Implication.(DOI.10.1093/heapol/czt040).

10. Martin D. et al. (2018).Canada's Universal Health-Care system: Achieving its Potential. (DOI.10.1016/50140-6736(18)3181-8).

11. Xu. j. c. (2018) More significance of TB-IGRA Except for the diagnose of Tuberculosis. (DOI.10.1002/j.cla.22183).

12. Alonso $\mathrm{j}$ et al. (2013).The Case for an International Patient -Reported Outcomes Measurement Information System(PROMIS) Initiative.

13. Schwartz Carolyn E. et al.(2005).Evaluation of the Missoula-VITAS Quality Of life Index--revised: Research tool or clinical tool.(DOI.10.1089/jpm.2005.8.121). 